Check for updates

Cite this: Mater. Adv., 2021, 2, 6104

Received 14th July 2021, Accepted 17th August 2021

DOI: $10.1039 / \mathrm{d} 1 \mathrm{ma00608h}$

rsc.li/materials-advances

\section{A novel turn-on fluorescent sensor for cyanide ions based on the charge transfer transition of phenothiazine/indolium compounds $\dagger$}

\author{
Yasuhiro Morikawa, ${ }^{a}$ Miku Hirabara, ${ }^{b}$ Keiji Nishiwaki, (D) *b Shigeo Suzuki ${ }^{\mathrm{bc}}$ and \\ Isao Nakanishibc
}

\begin{abstract}
A new fluorescent sensor combining phenothiazine and indolium, which reacts specifically with cyanide ions with a large Stokes shift and a good fluorescence quantum yield, was prepared. When $\mathrm{CN}^{-}$was added to an ethanol solution containing the synthesized sensor molecules, the solution color changed from purple to colorless, and fluorescence was emitted under $270 \mathrm{~nm}$ light irradiation. The mechanism of this luminescence, investigated via proton nuclear magnetic resonance, electrospray ionization mass spectrometry, and computational analysis, was defined as follows: the sensor undergoes nucleophilic addition of cyanide to the carbon of $\mathrm{C}=\mathrm{N}^{+}$in its indolium moiety, which limits the intramolecular charge transfer, resulting in a colorless transition and blue fluorescence. The specificity of the proposed sensor for cyanide has been confirmed through tests with 14 other anions $\left(\mathrm{F}^{-}, \mathrm{Cl}^{-}, \mathrm{Br}^{-}, \mathrm{I}^{-}, \mathrm{ClO}_{3}^{-}\right.$, $\mathrm{ClO}_{4}{ }^{-}, \mathrm{NO}_{2}{ }^{-}, \mathrm{NO}_{3}{ }^{-}, \mathrm{SO}_{3}{ }^{2-}, \mathrm{SO}_{4}{ }^{2-}, \mathrm{S}_{2} \mathrm{O}_{3}{ }^{2-}, \mathrm{S}^{2-}, \mathrm{N}_{3}^{-}$, and $\mathrm{SCN}^{-}$) and the detection limit is $0.02 \mu \mathrm{M}$ in the fluorescence spectrum. Changes in this sensor color can be detected by the naked eye and fluorescence emission can be induced via black light irradiation.
\end{abstract}

\section{Introduction}

The cyanide ion has extremely high toxicity but is relatively easy to obtain; it is used in the metal plating and plastics industries, and as a reagent in most laboratories. ${ }^{1}$ Given the concern about the health effects of $\mathrm{CN}^{-}$release into the environment, various technologies have been developed to detect $\mathrm{CN}^{-}$in drinking water and similar, mainly in the environmental field. $\mathrm{CN}^{-}$is also involved in serious crimes; ${ }^{2}$ for example, cyanide gas is produced in fires in addition to carbon monoxide. ${ }^{3}$ Therefore, $\mathrm{CN}^{-}$detection is extremely important to determine the cause of death in homicides and fires.

Thus, many instrumental analytical methods such as gas chromatography, mass spectrometry, liquid chromatography, and ion chromatography have been applied for the detection of $\mathrm{CN}^{-} ;^{4-15}$ however, these methods require expensive equipment,

\footnotetext{
${ }^{a}$ Forensic Science Laboratory, Kyoto Prefectural Police H.Q., 85-3, Yabunouchi-cho, Kamigyo-ku, Kyoto, 602-8550, Japan. E-mail: morikawa.fsl.kyoto@gmail.com

${ }^{b}$ Department of Pharmaceutical Sciences, Faculty of Pharmacy, Kindai University,

3-4-1, Kowakae, Higashiosaka, Osaka, 577-8502, Japan. E-mail:

k-nishi@phar.kindai.ac.jp

${ }^{c}$ Antiaging Center, Kindai University, Kindai University, 3-4-1, Kowakae,

Higashiosaka, Osaka, 577-8502, Japan

$\dagger$ Electronic supplementary information (ESI) available: Detailed experimental section, photography, UV-vis measurements, ${ }^{1} \mathrm{H}$ NMR analyses and other additional data. See DOI: 10.1039/d1ma00608h
}

advanced facilities, and excellent operation skills. Hence, several chemical sensors, including colorimetric sensors and fluorescent sensors that selectively react with $\mathrm{CN}^{-}$, have been recently developed for the rapid detection of $\mathrm{CN}^{-}$in the field. ${ }^{16}$ This approach has advantages such as shorter inspection time and lower cost, and allows simple and rapid on-site determination and is extremely useful for practical applications. Many sensors have been reported and most of them are based on the nucleophilic addition of $\mathrm{CN}^{-}$to their molecules ${ }^{17-20}$ or the coordination of cyano groups to metal reagents. ${ }^{16,21-23}$

In this study, we attempted to develop a turn-on fluorescent sensor for $\mathrm{CN}^{-}$, although fluorescence emission generally has a low detection limit; in other words, we designed a molecule that emits fluorescence when reacting with $\mathrm{CN}^{-}$. There have been many recent reports of detection reagents based on the mechanism of quenching of fluorescence that should be emitted via intramolecular charge transfer (ICT) and emitting fluorescence by cutting off the charge transfer..$^{24-26}$ In the molecular design, an electron-donating group and an electron-withdrawing group are connected by a carbon-carbon double bond to form a donor- $\pi$-acceptor system. Although various compounds are possible, we selected phenothiazine as the electron-donating group and an indolium salt as the electron-withdrawing group. A similar combination has been reported by El-Shishtawy et al. as a dimethine cyanine dye (PTZIS), a candidate for nonlinear optical materials. ${ }^{27}$ 
Phenothiazines emit fluorescence and have electron-donating properties, ${ }^{28-31}$ while many studies have reported the reaction of the indolium cation, which is a strong electron-withdrawing group, with $\mathrm{CN}^{-} .^{32-44}$ Therefore, we thought that a phenothiazine/indolium compound could also be applied for $\mathrm{CN}^{-}$ detection.

We synthesized a novel phenothiazine/indolium conjugated molecule (PI) as a $\mathrm{CN}^{-}$sensing dye; its color and fluorescence changes in response to $\mathrm{CN}^{-}$, as well as the selectivity to the target analyte, were also investigated. Then, its reaction mechanism was analyzed through proton nuclear magnetic resonance $\left({ }^{1} \mathrm{H}-\mathrm{NMR}\right)$, electrospray ionization mass spectrometry (ESI-MS), and computational analysis.

\section{Experimental}

\section{Chemicals and instruments}

Phenothiazine and $n$-octyl bromide were purchased from Nacali Tesque. 1,2,3,3-Tetramethyl-3H-indolium iodide was provided by Santa Cruz Biotechnology, Inc. Unless otherwise noted, all the chemicals were obtained from commercial suppliers and used without further purification.

Pure water was prepared with a Milli-Q system (Millipore Corporation). Fluorescence spectra and ultraviolet-visible light (UV-vis) absorption spectra were recorded on a FP-6200 (Jasco Corporation) and a UV-2700 spectrophotometer (Shimadzu Corporation), respectively. ESI-MS spectra were obtained using a micrOTOF II (Bruker Daltonics, Inc.) or an EXACTIVE mass spectrometer (Thermo Fisher Scientific). ${ }^{1} \mathrm{H}$-NMR spectra were measured with a JEOL JNM-AL400 (400 MHz) and a Bruker Avance (600 MHz) spectrometer in dimethyl sulfoxide (DMSO)$d_{6}$, with tetramethylsilane as an internal standard. Melting points were determined using a J-SCIENCE RFS-10 micro melting point apparatus and not corrected. A Jasco FT/IR-460 Plus spectrophotometer was used to measure infrared (IR) spectra.

\section{Synthesis of 2-(2-(10-hexyl-10H-phenothiazin-3-yl)vinyl)-1,3,3-} trimethyl-3H-indol-1-ium iodide (PI)

Scheme 1 shows the synthetic route of PI, which was modified from the method reported by El-Shishtawy et al. ${ }^{27}$

10-Octyl-10H-phenothiazine (1). Potassium hydroxide $(2.08 \mathrm{~g}, 370 \mathrm{mmol})$ was added portionwise to a solution of
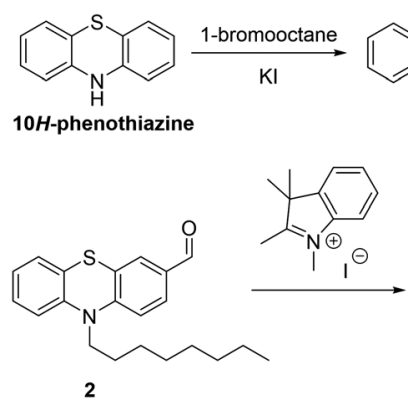

2
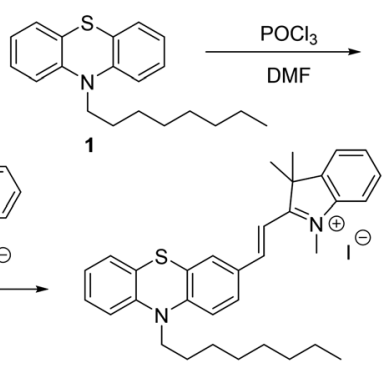

PI
Scheme 1 Synthesis of 2-(2-(10-hexyl-10H-phenothiazin-3-yl)vinyl)1,3,3-trimethyl-3H-indol-1-ium iodide (PI).
10H-phenothiazine (2.92 g, $14.6 \mathrm{mmol})$, 1-bromooctane (3.45 g, $17.8 \mathrm{mmol})$, and potassium iodide $(40.3 \mathrm{mg}, 0.24 \mathrm{mmol})$ in DMSO $(50 \mathrm{~mL})$. The reaction mixture was stirred at room temperature for $29 \mathrm{~h}$ and, then, poured into water $(200 \mathrm{~mL})$. The reaction mixture was extracted with chloroform. The combined chloroform layer was washed with saturated $\mathrm{NH}_{4} \mathrm{Cl}$ aqueous solution, dried over sodium sulfate, and concentrated in vacuo; the crude product was purified via silica gel flash column chromatography (hexane) to give $4.28 \mathrm{~g}, 94 \%$ yield as a colorless oil. The spectral data of $\mathbf{1}$ were in good agreement with the reported values. ${ }^{31}$

10-Octyl-10H-phenothiazine-3-carbaldehyde (2). Phosphoryl chloride $(2.74 \mathrm{~mL}, 29.3 \mathrm{mmol})$ was added dropwise at $0{ }^{\circ} \mathrm{C}$ to ice-cooled $N, N$-dimethylformamide $(5 \mathrm{~mL}, 64.6 \mathrm{mmol})$ under a nitrogen atmosphere. The reaction mixture was warmed up to room temperature, stirred for $10 \mathrm{~h}$, and then cooled down to $0{ }^{\circ} \mathrm{C}$, followed by the addition of a solution of 1 (2.19 g, $7.02 \mathrm{mmol})$ in $N, N$-dimethylformamide $(2.5 \mathrm{~mL})$. The resulting mixture was heated to $80{ }^{\circ} \mathrm{C}$, stirred for $18 \mathrm{~h}$, and then poured into ice water; afterward, it was basified by adding saturated potassium carbonate aqueous solution and extracted with chloroform. The combined organic phase was dried over sodium sulfate and concentrated in vacuo. The crude product was purified via flash column chromatography ( $n$-hexane/ethyl acetate $=9: 1)$ to give the title compound ( $2.02 \mathrm{~g}, 85 \%$ yield) as a yellow oil. The NMR and IR spectral data of 2 were in good agreement with the reported values. ${ }^{31}$

(E)-2-(2-(10-Hexyl-10H-phenothiazin-3-yl)vinyl)-1,3,3-trimethyl-3H-indol-1-ium iodide (PI). A solution of 2 (195.4 mg, $0.576 \mathrm{mmol}$ ) and 1,2,3,3-tetramethyl-3H-indolium iodide (190.5 $\mathrm{mg}, 0.632 \mathrm{mmol})$ in dry ethanol $(5.5 \mathrm{~mL})$ was stirred at $60{ }^{\circ} \mathrm{C}$ for $10 \mathrm{~h}$. After the solvent was removed by vacuuming, the residue was diluted with ethyl acetate, followed by the addition of $n$-hexane to the precipitate; the resulting precipitate was filtered off to give the title compound (300 $\mathrm{mg}, 84 \%$ yield) as a dark blue solid and, then, was further purified via recrystallization from a methanol-diethyl ether solution for the analysis.

${ }^{1} \mathrm{H}-\mathrm{NMR}\left(600 \mathrm{MHz}, \mathrm{CDCl}_{3}\right) \delta 8.40(\mathrm{~d}, J=8.1 \mathrm{~Hz}, 1 \mathrm{H}), 8.07$ $(\mathrm{d}, J=15.8 \mathrm{~Hz}, 1 \mathrm{H}), 7.73-7.42(\mathrm{~m}, 6 \mathrm{H}), 7.16(\mathrm{t}, J=7.3 \mathrm{~Hz}, 1 \mathrm{H})$, $7.07(\mathrm{~d}, J=7.2 \mathrm{~Hz}, 1 \mathrm{H}), 6.97(\mathrm{~d}, J=6.4 \mathrm{~Hz}, 2 \mathrm{H}), 6.88(\mathrm{~d}, J=$ $8.0 \mathrm{~Hz}, 1 \mathrm{H}), 4.38(\mathrm{~s}, 3 \mathrm{H}), 3.89(\mathrm{t}, J=6.7 \mathrm{~Hz}, 2 \mathrm{H}), 1.81(\mathrm{~s}, 8 \mathrm{H})$, 1.53-1.06 (m, 12H), $0.86(\mathrm{~d}, J=6.6 \mathrm{~Hz}, 3 \mathrm{H}) .{ }^{13} \mathrm{C}-\mathrm{NMR}(151 \mathrm{MHz}$, $\left.\mathrm{CDCl}_{3}\right) \delta 181.02,153.45,151.02,142.57,142.44,141.61,132.95$, 130.03 , 129.56, 129.14, 128.14, 127.67, 127.46, 124.37, 124.01, $123.17,122.47,116.23,115.78,114.15,109.57,51.90,48.36$, $36.88,31.71,29.20,29.15,27.22,26.84,26.77,22.61,14.10$. IR $\left(\mathrm{KBr}, \mathrm{cm}^{-1}\right)$ 2925, 2852, 1653, 1586, 1570, 1514, 1461. HRMS (ESI, positive mode, $m / z$ ): calculated for $\left[\mathrm{C}_{33} \mathrm{H}_{39} \mathrm{~N}_{2} \mathrm{~S}\right]^{+} 495.2828$, found 495.2818 .

Preparation of sample solutions for UV-vis and fluorescence measurements

$\mathrm{CN}^{-}$aqueous solution was added to $3 \mathrm{~mL}$ of $10 \mu \mathrm{M}$ PI solutions and each spectrum was measured. For optimization of the solvents, $6 \mu \mathrm{L}$ ( 2 equiv.) of a $10 \mathrm{mM} \mathrm{CN}^{-}$aqueous solution, for the determination of the quantitative relationship of 
$\mathrm{CN}^{-}$reacting with PI, $3-75 \mu \mathrm{L}\left(0.1-2\right.$ equiv.) of a $1 \mathrm{mM} \mathrm{CN}^{-}$ aqueous solution and for selectivity to various anions, $6 \mu \mathrm{L}$ of $10 \mathrm{mM}$ aqueous anion solution were added. Each aqueous anion solution was prepared by dissolving $100 \mu \mathrm{mol}$ of one among 15 inorganic salts (KCN, NaF, NaCl, $\mathrm{NaBr}, \mathrm{KI}, \mathrm{KClO}_{3}$, $\mathrm{KClO}_{4}, \mathrm{NaNO}_{2}, \mathrm{NaNO}_{3}, \mathrm{Na}_{2} \mathrm{SO}_{3}, \mathrm{Na}_{2} \mathrm{SO}_{4}, \mathrm{Na}_{2} \mathrm{~S}_{2} \mathrm{O}_{3}, \mathrm{Na}_{2} \mathrm{~S}, \mathrm{NaN}_{3}$, and $\mathrm{KSCN}$ ) in $10 \mathrm{~mL}$ of pure water.

\section{UV-Vis and fluorescence measurements}

A quartz cuvette with an optical path length of $1 \mathrm{~cm}$ was used for all the measurements. The UV-vis spectra were collected in the 300-800 $\mathrm{nm}$ range. The fluorescence spectra were recorded between 300 and $700 \mathrm{~nm}$ under $270 \mathrm{~nm}$ light irradiation. The fluorescence quantum yield $(\Phi)$ was determined via a comparative method by using $15 \mu \mathrm{M}$ quinine sulfate dihydrate $(F=0.55$ in $0.1 \mathrm{M} \mathrm{H}_{2} \mathrm{SO}_{4}$, where $\mathrm{F}$ is the integrated area under the corrected emission spectrum) as the standard according to the following equation: ${ }^{45}$

$$
\Phi_{x}=\Phi_{\text {st }}\left(A_{\mathrm{st}} / A_{x}\right)\left(F_{x} / F_{\mathrm{st}}\right)\left(\eta_{x} / \eta_{\mathrm{st}}\right)^{2}
$$

where $A$ is the absorbance at the excitation wavelength, $\eta$ is the refractive index of the solution, and the subscripts $x$ and st denote the unknown material and the standard, respectively.

\section{Job's plot measurement}

A $20 \mu \mathrm{M}$ solution of PI was prepared by dissolving in EtOH. Similarly, a $20 \mu \mathrm{M}$ solution of $\mathrm{CN}^{-}$was prepared by dissolving it in a $4: 1(\mathrm{v} / \mathrm{v})$ mixture of $\mathrm{EtOH} / \mathrm{H}_{2} \mathrm{O}$. Mixture solutions $(3.0 \mathrm{~mL})$ of $\mathbf{P I}$ and $\mathrm{CN}^{-}$at 11 different ratios from $0: 3$ to $3: 0$ $(\mathrm{v} / \mathrm{v})$ were prepared. After the solutions were allowed to stand for $10 \mathrm{~min}$, the absorbance at $555 \mathrm{~nm}$ was measured at room temperature. The difference between the initial absorbance $\left(A_{0}\right)$ and the obtained absorbance value $(A)$ was plotted against $[\mathbf{P I}] /$ $\left([\mathbf{P I}]+\left[\mathrm{CN}^{-}\right]\right)$, and the complex formation ratio was estimated from the abscissa at the maximum absorbance.

\section{Computational analysis}

The structural optimization and computational calculations for the ground state of PI were conducted via density functional theory (DFT) at the B3LYP/6-311G level of theory using Spartan' $10,{ }^{46}$ while those for the excited states of the fluorescent product produced by adding $\mathrm{CN}^{-}$to $\mathbf{P I}$ were performed at the B3LYP/6-31G level of theory by using the Gaussian 09 package. $^{47}$

\section{Results and discussion}

PI color and fluorescence changes when adding $\mathrm{CN}^{-}$in various solvents

Fig. 1 compares the absorption and fluorescence spectra of PI and the fluorescent product in different solvents. Therefore, PI was dissolved in various solvents, such as methanol, ethanol, acetonitrile, $\mathrm{N}, \mathrm{N}$-dimethylformamide, dimethyl sulfoxide, and chloroform; then, $\mathrm{CN}^{-}$( 2 equiv.) was added to these solutions, and the solution color change and fluorescence were analyzed. The excitation wavelength was $270 \mathrm{~nm}$ because it provided the maximum fluorescence when adding $\mathrm{CN}^{-}$to $\mathbf{P I}$ in the ethanol solution, and the corresponding fluorescence wavelength was $483 \mathrm{~nm}$, giving a larger Stokes shift (ESI, † Fig. S1). Fig. 2 also shows photographs of the color change of the solution and the fluorescence excited at $365 \mathrm{~nm}$. The PI solution in chloroform showed blue color, while in the others it showed purple. ElShishtawy et al. have observed the same phenomenon in PTZIS; they attributed this to the interaction of the iodide ion of the counter anion with the chlorine atoms in chloroform, which reduces the electron density of the iodide ion and destabilizes the ground state, enhancing the ICT characteristics and causing a bathochromic shift. ${ }^{27}$ When adding $\mathrm{CN}^{-}$, the color tone disappeared and all the solutions exhibited fluorescence with large Stokes shifts. The fluorescence intensity of the fluorescent product was weak in chloroform; we attributed this to the large bathochromic shift caused by ICT in that solvent. Among the tested solvents, dimethyl sulfoxide showed the strongest fluorescence intensity, but sufficient fluorescence intensity was observed in solvents other than chloroform also. In the case of chloroform, the dipole moment of the excited state of the fluorescent product was smaller due to the lower polarity of the solvent, and the maximum absorption wavelength has led to the bathochromic shift. Therefore, we decided to use ethanol, which is more practical and safer, in the subsequent experiments.
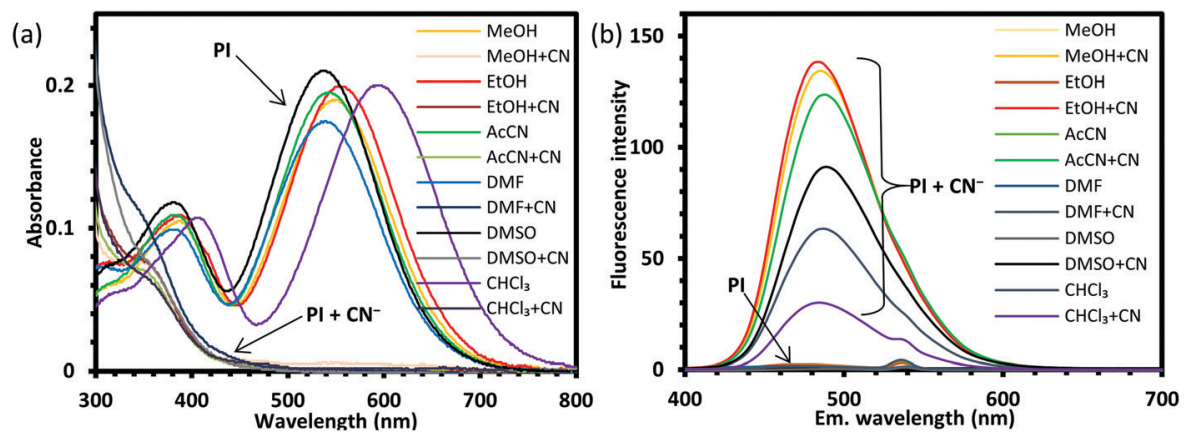

Fig. 1 (a) Absorption and (b) fluorescence spectra $\left(\lambda_{\mathrm{ex}}=270 \mathrm{~nm}\right)$ of 2-(2-(10-hexyl-10H-phenothiazin-3-yl)vinyl)-1,3,3-trimethyl-3H-indol-1-ium iodide $(\mathbf{P I}, 10 \mu \mathrm{M})$ in various solvents $(3 \mathrm{~mL})$ before and after adding $\mathrm{CN}^{-}$. 
(a)

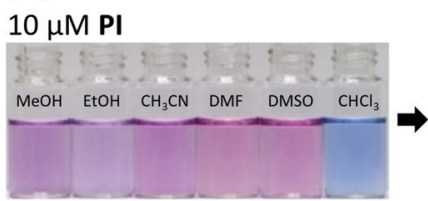

$10 \mu \mathrm{M} \mathbf{P I}+\mathrm{CN}^{-}$

(b)

\section{$10 \mu \mathrm{M} \mathbf{P I}$}

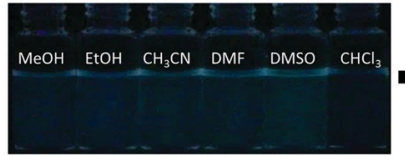

$10 \mu \mathrm{M} \mathrm{PI}+\mathrm{CN}^{-}$

$\mathrm{MEOH}$ EtOH $\mathrm{CH}_{3} \mathrm{CN}$ DMF $\mathrm{DMSO} \mathrm{CHCl}_{3}$

$\mathrm{MeOH} \quad \mathrm{EHOH} \quad \mathrm{CH}_{3} \mathrm{CN}$ DMF $\mathrm{OMSO} \mathrm{CHCl}_{3}$

Fig. 2 (a) Changes in the color and (b) the fluorescence excited by black light $(\lambda=365 \mathrm{~nm})$ of 2-(2-(10-hexyl-10H-phenothiazin-3-yl)vinyl)-1,3,3trimethyl-3H-indol-1-ium iodide (PI, $10 \mu \mathrm{M})$ in various solvents $(3 \mathrm{~mL})$, before and after adding $\mathrm{CN}^{-}$.

\section{Changes in the absorption and fluorescence spectra of PI when} adding $\mathrm{CN}^{-}$

The quantitative relation between $\mathbf{P I}$ and $\mathrm{CN}^{-}$was studied via UV-vis and fluorescence spectroscopy analyses. The absorbance at 390 and $555 \mathrm{~nm}$ decreased with increasing $\mathrm{CN}^{-}$concentration (Fig. 3(a)), while the fluorescence increased with it (Fig. 3(b)). The fluorescence intensity at $483 \mathrm{~nm}$ varied linearly with the $\mathrm{CN}^{-}$concentration $\left(R^{2}=0.9945\right)$ (ESI, $\dagger$ Fig. S2). The limit of detection (LOD), calculated as $3.3 s / a$, where $s$ is the standard deviation of the signal in the blank material and $a$ is
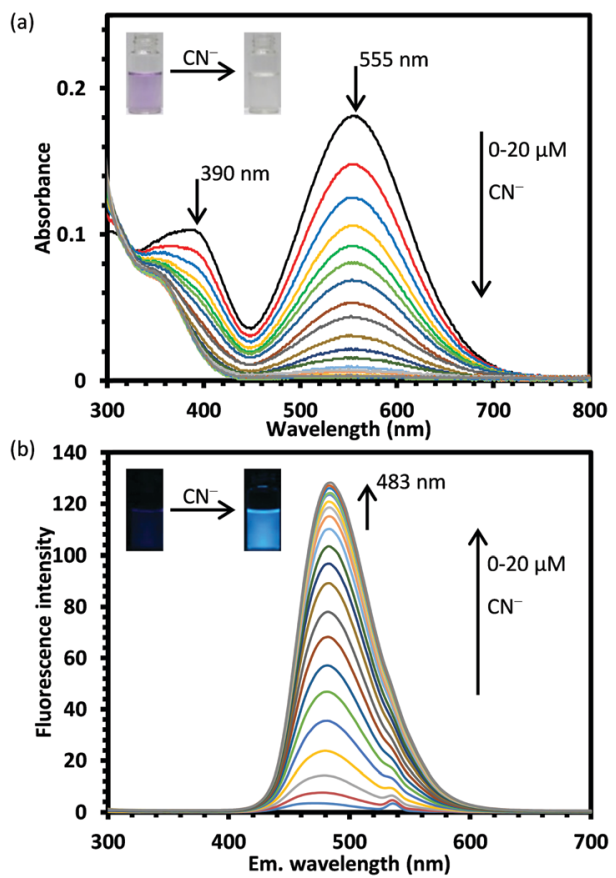

Fig. 3 (a) Absorption and (b) fluorescence spectra $\left(\lambda_{\text {ex }}=270 \mathrm{~nm}\right)$ of $10 \mu \mathrm{M}$ 2-(2-(10-hexyl-10H-phenothiazin-3-yl)vinyl)-1,3,3-trimethyl-3H-indol-1ium iodide when adding various concentrations of $\mathrm{CN}^{-}$. The insets in (a) and (b) show the changes in the solution color and fluorescence, respectively, when adding $\mathrm{CN}^{-}$. the slope of the calibration curve near the detection limit, was $0.29 \mu \mathrm{M}$ by UV-vis and $0.02 \mu \mathrm{M}$ by UV-vis fluorescence spectroscopy. Although many fluorescent sensors for $\mathrm{CN}^{-}$detection have been reported, ${ }^{48}$ PI showed relatively good sensitivity compared with these sensors (ESI, $\dagger$ Table S1). The $\mathrm{CN}^{-}$concentration in human blood is toxic when it exceeds $19 \mu \mathrm{M},{ }^{49,50}$ but the World Health Organization (WHO) has set the maximum concentration of $\mathrm{CN}^{-}$in drinking water to be $1.9 \mu \mathrm{M}^{51}$ Therefore, PI could be applied in the environmental field or for forensic analysis because the LOD is much lower than these concentrations.

The reaction kinetics between $\mathbf{P I}$ and $\mathrm{CN}^{-}$were also investigated. $\mathrm{CN}^{-}(20 \mu \mathrm{M}, 2$ equiv.) was added to a $10 \mu \mathrm{M}$ PI solution and the change in the fluorescence intensity was measured over time (ESI, $\dagger$ Fig. S3(a)). The reaction started upon the $\mathrm{CN}^{-}$ addition and reached a steady state after $100 \mathrm{~s}$. When $\ln \left[\left(\right.\right.$ Int $_{\mathrm{t}}$ - Int $\left.\left.t_{\max }\right)\right]$, where $I n t_{\max }$ is the emission intensity at the steady state and Int $t_{\mathrm{t}}$ is the intensity at time $t$, was plotted versus time, a linear fit was obtained, as shown in Fig. S3(b) (ESI $\dagger$ ), demonstrating that the reaction follows pseudo-first-order kinetics. The rate constant of this reaction $\left(K_{\text {obs }}\right)$, calculated via the above reaction equation, was $0.0307 \mathrm{~s}^{-1}$ (ESI, $\dagger$ Fig. S3(b)). Then, the reaction rate was determined in the same way for $\mathrm{CN}^{-}$and less than one equivalent of solutions containing 10, 7.5, and $5 \mu \mathrm{M}$ of $\mathrm{CN}^{-}$were added to a $10 \mu \mathrm{M}$ solution of PI. The fluorescence intensity increased linearly up to $50 \mathrm{~s}$ and then slowly; after 20 minutes of measurement, no steady state was reached, but the fluorescence intensity of each solution was proportional to the respective $\mathrm{CN}^{-}$concentration (ESI, $\dagger$ Fig. S4).

\section{Selectivity of PI for different anions}

To investigate the selectivity of $\mathbf{P I}$ for anions other than $\mathrm{CN}^{-}, 15$ species of anions including $\mathrm{CN}^{-}$were added to the PI solution and their behavior was observed. In addition, $\mathrm{CN}^{-}$and other anions were added at the same time, and anti-interference experiments were also performed. As a result, the purple color disappeared and fluorescence was observed only when adding $\mathrm{CN}^{-}$(Fig. 4). The absorbance intensity at $555 \mathrm{~nm}$ and the fluorescence intensity at $483 \mathrm{~nm}$ excited at $273 \mathrm{~nm}$ were also measured (Fig. 5, ESI, $\dagger$ Fig. S5 and S6). Among the other 14 anions, $\mathrm{S}^{2-}$ induced a change in the solution color, which became lighter, and fluorescence emission, but the fluorescence intensity was about $1 / 7$ that obtained for $\mathrm{CN}^{-}$.

To investigate the reactivity of PI to $\mathrm{S}^{2-}$, various $\mathrm{S}^{2-}$ concentrations (1-16 equiv.) were added to PI (ESI, $\dagger$ Fig. S7); the purple color disappeared with increasing $\mathrm{S}^{2-}$ concentration and the absorption spectrum became constant at 4 equiv., but the fluorescence did not increase with it. The mass spectrum of the reaction solution was measured, but only the peak of the cationic component of PI was observed, that is, the peak of the PI/ $\mathrm{S}^{2-}$ conjugated compound was not observed. These results indicate that $\mathrm{S}^{2-}$ reacted with PI, but its reactivity is low. Besides, the estimated quantum yield of the reaction products was very low. Thus, $\mathbf{P I}$ could discriminate between $\mathrm{CN}^{-}$and $\mathrm{S}^{2-}$ and, in terms of fluorescence, it has specificity for $\mathrm{CN}^{-}$. 
(a)

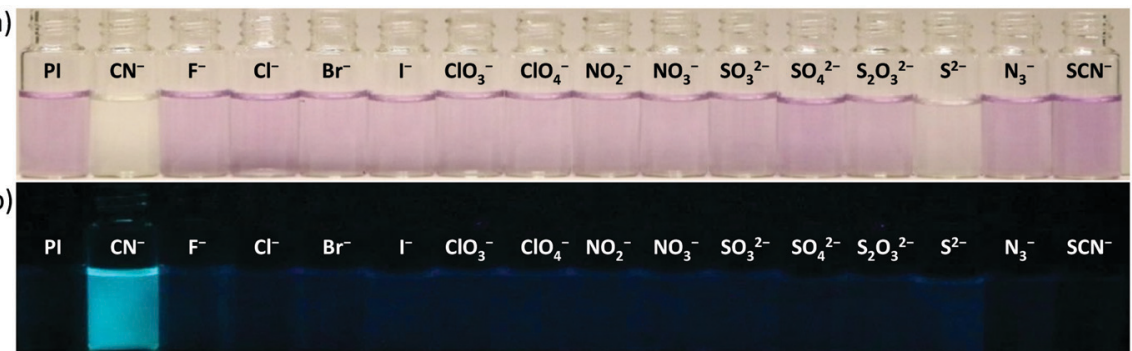

Fig. 4 (a) Changes in the color and (b) the fluorescence excited by black light $(\lambda=365 \mathrm{~nm})$ of 2-(2-(10-hexyl-10H-phenothiazin-3-yl)vinyl)-1,3,3trimethyl-3H-indol-1-ium iodide (PI) when adding 2 equiv. of different anions.
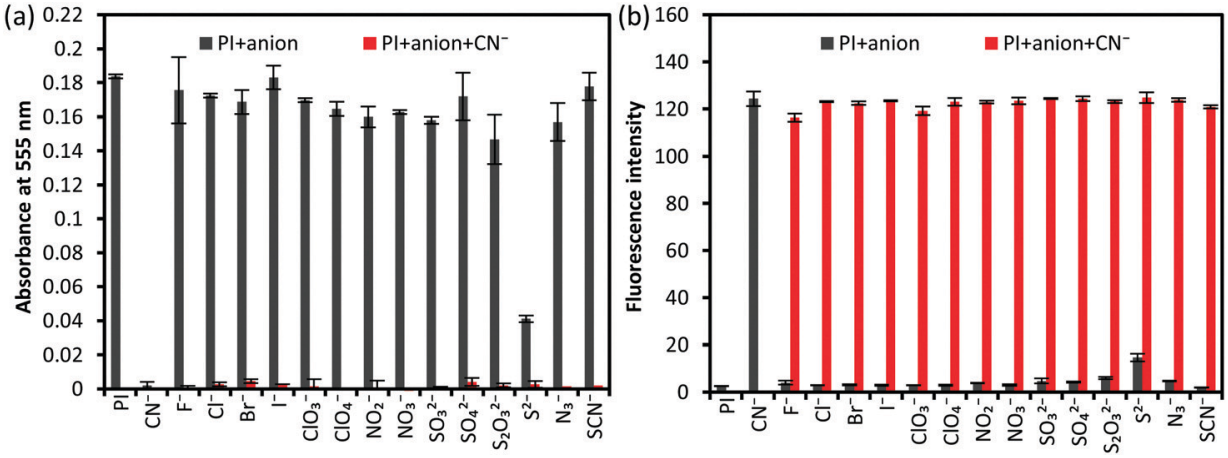

Fig. 5 (a) Changes in the absorbance at $555 \mathrm{~nm}$ and (b) fluorescence intensities of 2-(2-(10-hexyl-10H-phenothiazin-3-yl)vinyl)-1,3,3-trimethyl-3Hindol-1-ium iodide (PI) at $483 \mathrm{~nm}$ at an excitation wavelength of $270 \mathrm{~nm}$ when adding 2 equiv. of different anions.

\section{Identification of the fluorescent compound and sensing} mechanism

To determine the structure of the $\mathbf{P I} / \mathrm{CN}$ conjugated compound, we performed ${ }^{1} \mathrm{H}-\mathrm{NMR}$ and MS measurements after the $\mathrm{CN}^{-}$ addition to PI. The ratios of the reactants were determined via
Job's plots. A ${ }^{1} \mathrm{H}-\mathrm{NMR}$ titration study in DMSO- $d_{6}$ was conducted to acquire an insight into the proposed reaction pathway of $\mathrm{CN}^{-}$and PI (Fig. 6). $\mathrm{A} \mathrm{CN}^{-}$solution was added at 0.251.25 equiv. to PI solution incrementally. According to the amount of $\mathrm{CN}^{-}$added, the signals at 8.30 and $7.52 \mathrm{ppm}$

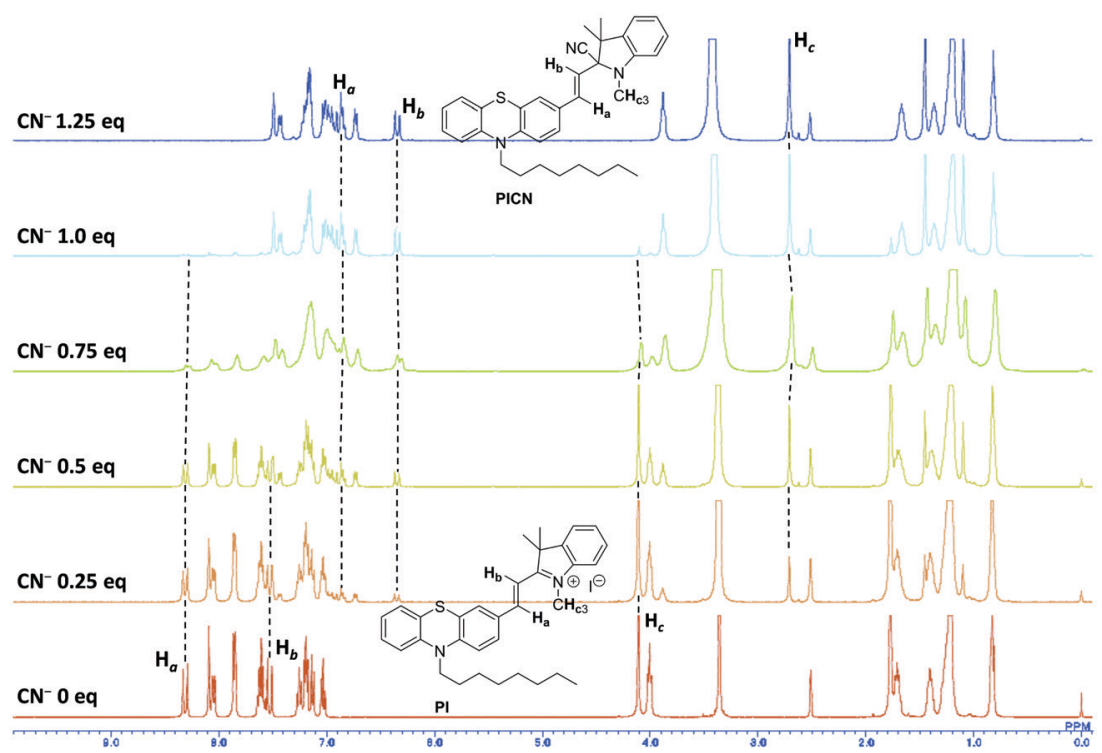

Fig. 6 Proton nuclear magnetic resonance spectra of 2-(2-(10-hexyl-10H-phenothiazin-3-yl)vinyl)-1,3,3-trimethyl-3H-indol-1-ium iodide before and after the $\mathrm{CN}^{-}$addition, in various concentrations, in dimethyl sulfoxide- $d_{6}$. 


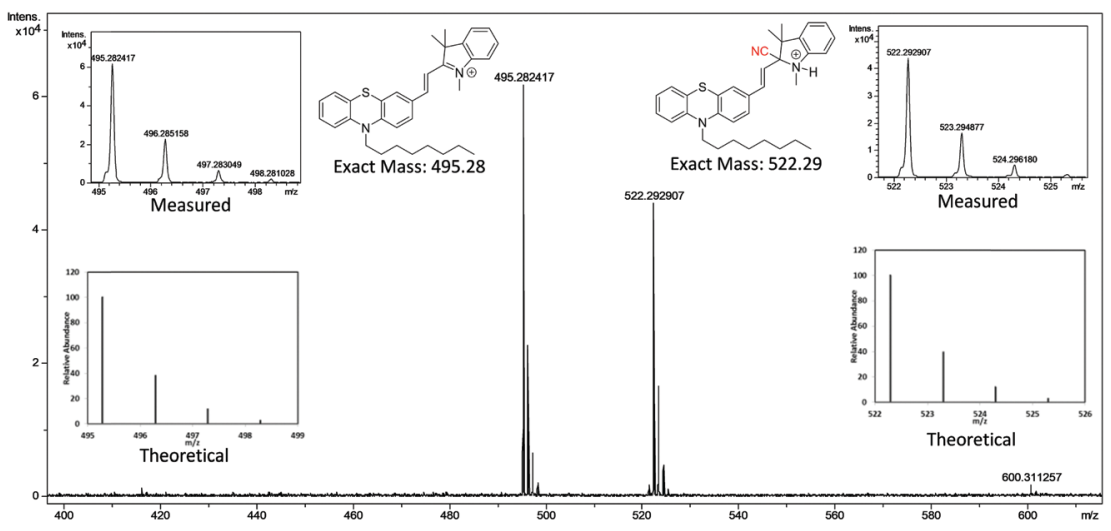

Fig. 7 Electrospray ionization mass spectrum of 2-(2-(10-hexyl-10H-phenothiazin-3-yl)vinyl)-1,3,3-trimethyl-3H-indol-1-ium iodide (PI) with $\mathrm{CN}^{-}$ (positive ion mode); the insets show the measured and theoretical values of PI and (E)-1,3,3-trimethyl-2-(2-(10-octyl-10H-phenothiazin-3yl)vinyl)indoline-2-carbonitrile, respectively.

corresponding to the protons on the $(E)$-olefin moiety $(J=16 \mathrm{~Hz})$ shifted to 6.86 and $6.33 \mathrm{ppm}(J=16 \mathrm{~Hz})$, respectively, and the signal of the methyl protons on the nitrogen atom shifted from 4.11 to $2.71 \mathrm{ppm}$. These results suggest that the chemical shifts of these hydrogens changed significantly because indolium was converted into a tertiary amine upon the $\mathrm{CN}^{-}$addition and the olefin moiety conjugated to indolium ceased to be conjugated to the resulting tertiary amine. The binding mechanism between $\mathbf{P I}$ and $\mathrm{CN}^{-}$was further confirmed via the MS measurements. The ESI-MS spectra of the PI/CN conjugated compound revealed the cationic component of PI (MW: 495.28) and [M $+\mathrm{H}]^{+}$of the $\mathrm{CN}^{-}$adduct of PI (cationic component) (MW: 522.29) (Fig. 7). Moreover, their isotopic ratio was consistent with the theoretical value. This result supports the nucleophilic addition of $\mathrm{CN}^{-}$to the PI molecule, and the detection of the cationic component of PI as a fragment ion peak suggests that the cation is very stable.

Moreover, to confirm the generation constants of $\mathbf{P I}$ and $\mathrm{CN}^{-}$, we analyzed the generation ratio via Job's plot analysis. The maximum value was observed at 0.5 , which means that PI and $\mathrm{CN}^{-}$ react at a ratio of $1: 1$ (ESI, $\dagger$ Fig. S8). From these results, we concluded that the reaction between $\mathbf{P I}$ and $\mathrm{CN}^{-}$is a $\mathrm{CN}^{-}$addition to the $\mathrm{C}=\mathrm{N}^{+}$of the indolium ring, yielding (E)-1,3,3-trimethyl-2-(2(10-octyl-10H-phenothiazin-3-yl)vinyl)indoline-2-carbonitrile (PICN). As reported for many $\mathrm{CN}^{-}$sensors containing indolium, the $\mathrm{CN}^{-}$ addition to the carbon of the double bond of indolium breaks the conjugation between phenothiazine and indolium, linked by a double bond, inhibiting the ICT from the electron-donating (phenothiazine) to the electron-withdrawing group (indolium) (Scheme 2). As a result, quenching in the visible part and fluorescence emission should occur. The Stokes shift and $\Phi$ of PICN were, respectively, $118 \mathrm{~nm}$ and 0.60 relative to quinine ( $\Phi=0.55$ in $0.1 \mathrm{M}$ $\left.\mathrm{H}_{2} \mathrm{SO}_{4}\right)(\mathrm{ESI}, \dagger$ Table $\mathrm{S} 2)$. Therefore, PI reacts with the cyanide ion with a large Stokes shift and a good $\Phi$.

\section{Computational analysis}

The frontier orbitals were obtained through DFT calculations for a compound where the $n$-octyl group on the phenothiazine

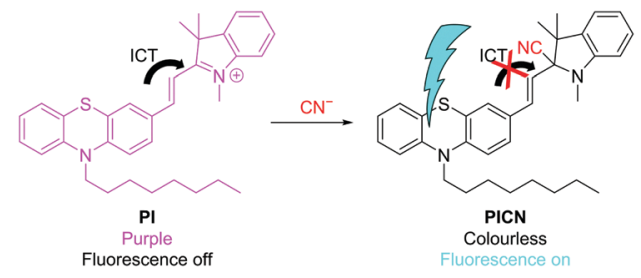

Scheme 2 Plausible light-emitting mechanism of 2-(2-(10-hexyl-10Hphenothiazin-3-yl)vinyl)-1,3,3-trimethyl-3H-indol-1-ium iodide (PI) with $\mathrm{CN}^{-}$.

of PI is replaced with a methyl group to reduce the computational cost. The higher occupied molecular orbital (HOMO) of PI was widely distributed from the phenothiazine ring to the $\mathrm{C}=\mathrm{N}^{+}$site of the indolium group (Fig. 8); this suggests that ICT is occurring, which may have resulted in the loss of fluorescence. The gap between the HOMO and lower unoccupied molecular orbital (LUMO) was $2.10 \mathrm{eV}$ (590 nm), which correlates well with the experimental data. The large coefficient on the carbon of the $\mathrm{C}=\mathrm{N}^{+}$moiety in the LUMO also explains the nucleophilic addition of $\mathrm{CN}^{-}$to it. The HOMO-LUMO gaps of both the enantiomers of PICN were also calculated and they showed the same value (3.92 eV), higher than that of PI (Fig. 9). This increase in the energy gap implies the breakage of the $\pi$-conjugation between the phenothiazine and indolium moieties and it implies that the ICT process has been stopped.

Time-dependent DFT calculations for the excited state of PICN were also performed to verify the emission. The fluorescence wavelength of both PICN enantiomers was $481 \mathrm{~nm}$, which

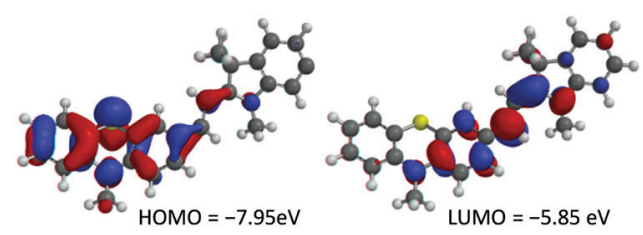

Fig. 8 Frontier molecular orbitals and their energies of 2-(2-(10-hexyl$10 \mathrm{H}$-phenothiazin-3-yl)vinyl)-1,3,3-trimethyl-3H-indol-1-ium iodide (PI). 

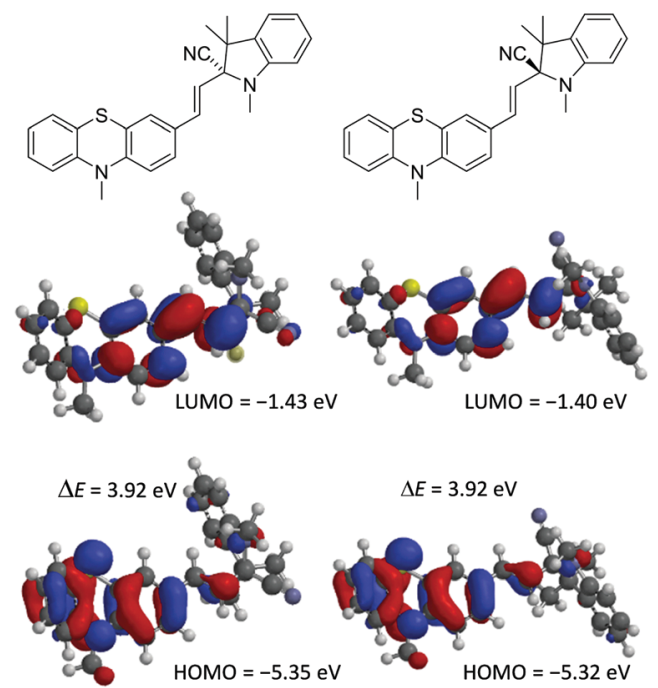

Fig. 9 Frontier molecular orbitals of (E)-1,3,3-trimethyl-2-(2-(10-octyl$10 \mathrm{H}$-phenothiazin-3-yl)vinyl)indoline-2-carbonitrile (PICN) and their energies.

is in good agreement with the measured values. This result supports the sensing mechanism proposed in the previous section.

\section{Conclusions}

We designed and synthesized a new fluorescent chemical sensor, PI, and investigated its response to $\mathrm{CN}^{-}$. PI showed a clear color change and fluorescence when adding $\mathrm{CN}^{-}$, as well as sufficient sensitivity with a LOD of $0.02 \mu \mathrm{M}$, which is below the maximum value established by the WHO and the toxic $\mathrm{CN}^{-}$ concentration in human blood. Among 15 anions, PI reacted only with $\mathrm{CN}^{-}$; that is, it emitted fluorescence specifically in response to $\mathrm{CN}^{-}$and its fluorescence intensity increased linearly when adding $0-1.3$ equiv. $\mathrm{CN}^{-}$. The mechanism of fluorescence emission was analyzed through various spectral measurements and DFT. We found that it was caused by ICT disruption. Moreover, PI can react with $\mathrm{CN}^{-}$in ethanol and, thus, can be used for on-site determination. Therefore, it is a promising candidate for a practical $\mathrm{CN}^{-}$sensor.

\section{Author contributions}

Yasuhiro Morikawa and Keiji Nishiwaki: conceptualization, synthesis, analysis, and writing original draft. Miku Hirabara: synthesis, Shigeo Suzuki conceptualization and review \& editing, Isao Nakanishi: resource.

\section{Conflicts of interest}

There are no conflicts to declare.

\section{Acknowledgements}

This study was supported by the MEXT-Supported Program for the Strategic Research Foundation at Private Universities (S1411037, 2014-2018).

\section{Notes and references}

1 F. P. Simeonova and L. Fishbein, Hydrog. cyanide cyanides Hum. Heal. Asp., World Heal. Organ. Concise Int. Chem. Assess. Doc. 61, Geneva, 2004, pp. 4-5. http//www.who.int/ ipcs/publications/cicad/en/cicad61.pdf (accessed April 22, 2021).

2 S. Yasuo, Anal. Chem., 2002, 74, 134A-141A.

3 Y. Alarie, Crit. Rev. Toxicol., 2002, 32, 259-289.

4 Y. Seto, N. Tsunoda, H. Ohta and T. Shinohara, Anal. Chim. Acta, 1993, 276, 247-259.

5 V. Gambaro, S. Arnoldi, E. Casagni, L. Dell'Acqua, C. Pecoraro and R. Froldi, J. Forensic Sci., 2007, 52, 1401-1404.

6 R. K. Bhandari, E. Manandhar, R. P. Oda, G. A. Rockwood and B. A. Logue, Anal. Bioanal. Chem., 2014, 406, 727-734.

7 D. R. Goud, K. Sinha Roy, D. Pardasani, A. K. Purohit, V. K. Tak and D. K. Dubey, Anal. Methods, 2020, 12, 5839-5845.

8 O. Destanoğlu and İ. Ateş, J. Serb. Chem. Soc., 2021, 86, 77-90.

9 G. Liu, J. Liu, K. Hara, Y. Wang, Y. Yu, L. Gao and L. Li, J. Chromatogr. B: Anal. Technol. Biomed. Life Sci., 2009, 877, 3054-3058.

10 P. Luo, Y. Yu, D. Wu, X. Li, C. Dai, X. Chen, G. Li and Y. Wu, Anal. Methods, 2019, 11, 2983-2990.

11 M. Madmon, A. Shifrovich, S. Y. Tamar and A. Weissberg, Int, J. Mass Spectrom., 2021, 463, 116553.

12 C. Lacroix, E. Saussereau, F. Boulanger and J. P. Goullé, J. Anal. Toxicol., 2011, 35, 143-147.

13 A. Kumar Meher, N. Labhsetwar and A. Bansiwal, Food Chem., 2018, 240, 131-138.

14 M. Ding and K. Wang, R. Soc. Open Sci., 2018, 5, 172128.

15 E. Jaszczak, S. Narkowicz, J. Namieśnik and Ż. Polkowska, Monatsh. Chem., 2017, 148, 1645-1649.

16 Y. Morikawa, K. Nishiwaki, S. Suzuki, N. Yasaka, Y. Okada and I. Nakanishi, Analyst, 2020, 145, 7759-7764.

17 Z. M. Dong, H. Ren, J. N. Wang and Y. Wang, Microchem. J., 2020, 155, 104676.

18 H. Fang, W. J. Qu, H. H. Yang, J. X. He, H. Yao, Q. Lin, T. B. Wei and Y. M. Zhang, Dyes Pigm., 2020, 174, 108066.

19 G. Sun, W. Chen, Y. Liu, X. Jin, Z. Zhang and J. Su, Dyes Pigm., 2020, 176, 108224.

20 K. Deng, L. Wang, Q. Xia, R. Liu and J. Qu, Sens. Actuators, B, 2019, 296, 126645.

21 K. P. Divya, S. Sreejith, B. Balakrishna, P. Jayamurthy, P. Anees and A. Ajayaghosh, Chem. Commun., 2010, 46, 6069-6071.

22 A. Bencini and V. Lippolis, Environ. Sci. Pollut. Res., 2016, 23, 24451-24475.

23 X. Lou, L. Zhang and Z. Li, Chem. Commun., 2008, 44, 5848-5850. 
24 T. T. Tran, J. Rabah, M. H. Ha-Thi, E. Allard, S. Nizinski, G. Burdzinski, S. Aloïse, H. Fensterbank, K. Baczko, H. Nasrallah, A. Vallée, G. Clavier, F. Miomandre, T. Pino and R. Méallet-Renault, J. Phys. Chem. B, 2020, 124, 9396-9410.

25 T. Tajima, S. Okabe and Y. Takaguchi, Bull. Chem. Soc. Jpn., 2020, 93, 745-750.

26 W. Thongyod, C. Buranachai, T. Pengpan and C. Punwong, Phys. Chem. Chem. Phys., 2019, 21, 16258-16269.

27 R. M. El-Shishtawy, F. A. M. Al-Zahrani, S. M. Afzal, M. A. N. Razvi, Z. M. Al-Amshany, A. H. Bakry and A. M. Asiri, $R S C$ Adv., 2016, 6, 91546-91556.

28 K. Kaur, R. Saini, A. Kumar, V. Luxami, N. Kaur, P. Singh and S. Kumar, Coord. Chem. Rev., 2020, 256, 1992-2028.

29 A. M. Al-Soliemy, J. Mol. Struct., 2019, 1179, 525-531.

30 F. A. M. Al-Zahrani, R. M. El-Shishtawy, A. M. Asiri, A. M. Al-Soliemy, K. A. Mellah, N. S. E. Ahmed and A. Jedidi, BMC Chem., 2020, 14, 1-11.

31 R. M. El-shishtawy, F. A. M. Al-zahrani, Z. M. Al-amshany and A. M. Asiri, Sens. Actuators, B, 2017, 240, 288-296.

32 Y. Zhang, D. Yu and G. Feng, RSC Adv., 2014, 4, 14752-14757.

33 J. H. Park, R. Manivannan, P. Jayasudha and Y. A. Son, Spectrochim. Acta, Part A, 2020, 233, 118190.

34 J. Li, S. Yuan, J. S. Qin, J. Pang, P. Zhang, Y. Zhang, Y. Huang, H. F. Drake, W. R. Liu and H. C. Zhou, Angew. Chem., Int. Ed., 2020, 59, 9319-9323.

35 H. Pan, Y. Liu, S. Liu, Z. Ou, H. Chen and H. Li, Talanta, 2019, 202, 329-335.

36 S. Maji, B. Chowdhury, S. Pal and P. Ghosh, Inorg. Chim. Acta, 2018, 483, 321-328.

37 Y. Liu, D. Qiu, H. Pan, M. Li, H. Chen and H. Li, J. Photochem. Photobiol., A, 2018, 364, 151-158.

38 J. Chao, Z. Li, Y. Zhang, F. Huo, C. Yin, H. Tong and Y. Liu, Sens. Actuators, B, 2016, 228, 192-199.

39 L. Hou, F. Li, J. Guo, X. Zhang, X. Kong, X. T. Cui, C. Dong, Y. Wang and S. Shuang, J. Mater. Chem. B, 2019, 7, 4620-4629.

40 Y. Yu, T. Shu, B. Yu, Y. Deng, C. Fu, Y. Gao, C. Dong and Y. Ruan, Sens. Actuators, B, 2018, 255, 3170-3178.

41 N. Yadav and A. K. Singh, New J. Chem., 2018, 42, 6023-6033.
42 Y. Yang, C. Yin, F. Huo, Y. Zhang and J. Chao, Sens. Actuators, B, 2014, 203, 596-601.

43 S. Cheng, X. Pan, M. Shi, T. Su, C. Zhang, W. Zhao and W. Dong, Spectrochim. Acta, Part A, 2020, 228, 117710.

44 X. Huang, X. Gu, G. Zhang and D. Zhang, Chem. Commun., 2012, 48, 12195-12197.

45 M. M. Sartin, F. Camerel, R. Ziessel and A. J. Bard, J. Phys. Chem. C, 2008, 112, 10833-10841.

46 Spartan'10, Wavefunction, Inc., Irvine, CA, 2011.

47 M. J. Frisch, G. W. Trucks, H. B. Schlegel, G. E. Scuseria, M. A. Robb, J. R. Cheeseman, G. Scalmani, V. Barone, B. Mennucci, G. A. Petersson, H. Nakatsuji, M. Caricato, X. Li, H. P. Hratchian, A. F. Izmaylov, J. Bloin, G. Zheng, J. L. Sonnenberg, M. Hada, M. Ehara, K. Toyota, R. Fukuda, J. Hasegawa, M. Ishida, T. Nakajima, Y. Honda, O. Kitao, H. Nakai, T. Vreven, J. A. Montgomery Jr., J. E. Peralta, F. Ogliaro, M. Bearpark, J. J. Heyd, E. Brothers, K. N. Kudin, V. N. Staroverov, R. Kobayashi, J. Normand, K. Raghavachari, A. Rendell, J. C. Burant, S. S. Iyengar, J. Tomasi, M. Cossi, N. Rega, J. M. Millam, M. Klene, J. E. Knox, B. Cross, V. Bakken, C. Adamo, J. Jaramillo, R. Gomperts, R. E. Stratmann, O. Yazyev, A. J. Austin, R. Cammi, C. Pomelli, J. W. Ochterski, R. L. Martin, K. Morokuma, V. G. Zakrzewski, G. A. Voth, P. Salvador, J. J. Dannenberg, S. Dapprich, A. D. Daniels, Ö. Farkas, J. B. Foresman, J. V. Ortiz, J. Cioslowski and D. J. Fox, 2010, Gaussian 09, Revision C.01, Gaussian, Inc., Wallingford CT.

48 R. Bhaskar and S. Sarveswari, Inorg. Chem. Commun., 2019, 102, 83-89.

49 R. Jackson and B. A. Logue, Anal. Chim. Acta, 2017, 960, 18-39.

50 The Agency for Toxic Substances and Disease Registry. Toxicological profile for cyanide, US Department of Health and Human Services, Atlanta, GA, http:/www.atsdr.cdc.gov/ toxprofiles/tp8-c1.pdf p. 4.

51 Guidelines for drinking-water quality, 4th edition, incorporating the 1st addendum, World Health Organization, Geneva, Switzerland, 4th ed., 2017. 